\title{
Por que não distinguir sentido próprio de sentido figurado em Saussure e em Ducrot?
}

\author{
Pourquoi ne pas distinguer le sens propre et le sens figuré chez \\ Saussure et chez Ducrot? \\ Lauro Gomes \\ Leci Borges Barbisan
}

Pontifícia Universidade Católica do Rio Grande do Sul - PUCRS - Porto Alegre - Rio Grande do Sul - Brasil

\begin{abstract}
Resumo: Este texto propõe uma reflexão sobre as noções clássicas de sentido próprio e de sentido figurado, com base em princípios e conceitos apresentados por Ferdinand de Saussure, no Curso de linguística geral e nos Escritos de linguística geral, e por Oswald Ducrot, a propósito da postulação da tese de que a argumentação está na língua. Dentre os conceitos saussurianos mais importantes para as reflexões feitas ao longo deste texto, destacam-se os de arbitrário, de relação e de valor. Ganha o acento este último conceito da teoria de Saussure, visto que é baseado nele e na noção de alteridade apresentada por Platão, em $O$ Sofista, que Ducrot rejeita a existência de um aspecto objetivo na linguagem e une os aspectos subjetivo e intersubjetivo - constitutivos do sentido de enunciados - no que chamou de valor argumentativo. Mantendo-se, portanto, fiel ao modo saussuriano de olhar para a linguagem, Ducrot construiu a Teoria da Argumentação na Língua - « L'Argumentation Dans la Langue »- e defende, até o momento atual da teoria, a hipótese que rejeita a distinção dos tradicionalmente chamados sentidos denotativo e conotativo.
\end{abstract}

Palavras-chave: sentido próprio, sentido figurado, valor, alteridade, Semântica Argumentativa.

Résumé: Ce texte propose une réflexion sur les notions classiques de sens propre et sens figuré, sur la base de principes et de concepts présentés par Ferdinand de Saussure, dans le Cours de linguistique générale et dans les Écrits de linguistique générale, et par Oswald Ducrot, en ce qui concerne la proposition de la thèse selon laquelle l'argumentation est dans la langue. Parmi les concepts saussuriens les plus importants pour les réflexions produites dans ce texte, on détache ceux concernant l'arbitraire, la relation et la valeur.Ce dernier concept de la théorie de Saussure est mis en relief, étant donné que Ducrot se fonde sur ce concept et sur la notion d'altérité présentée par Platon, dans Le Sophiste, pour refuser l'existence d'un aspect objectif dans le langage et unir les aspects subjectif et intersubjectif - constitutifs du sens d'énoncés - dans ce qu'il a appelé valeur argumentative. En restant, donc, fidèle au mode saussurien de regarder le langage, Ducrot a construit « L'Argumentation Dans la Langue » et défend, jusqu'au moment actuel de la théorie, l'hypothèse qui refuse la distinction des sens traditionnellement appelés dénotatif et conotatif.

Mots-clés: sens propre, sens figuré, valeur, altérité, Sémantique Argumentative. 


\section{Introdução}

Há bastante tempo, a distinção clássica entre sentido próprio e sentido figurado tem sido tema de discussão em linguística e em literatura. Trata-se de uma questão de interesse para ambas as áreas, pois tanto a estilística quanto a teoria e a crítica literária fundamentam-se nessa dicotomia, principalmente quando buscam estabelecer as fronteiras entre a linguagem ordinária e a linguagem literária, por exemplo. No texto $A$ retórica antiga, Roland Barthes (1975, p. 216-217) faz um resgate histórico das noções de sentido próprio e de sentido figurado, observando que essa dicotomia decorre das noções de nacional/estrangeiro e de normal/estranho. Enquanto, por um lado, o sentido próprio era tido como a primeira significação da palavra, o sentido figurado, por outro lado, era uma significação segunda, estabelecida pelo uso da língua.

Inscrito na problemática que envolve a constituição do sentido na linguagem, este texto busca explicitar a impossibilidade de distinção de sentido próprio de sentido figurado, com base em princípios e conceitos propostos por Ferdinand de Saussure $^{1}$, em seus trabalhos que fundam a linguística moderna, e por Oswald Ducrot em seus trabalhos sobre a semântica linguística². Por se tratar de um artigo teórico, são revisitados, ao longo deste texto, manuscritos da primeira parte do livro Escritos de linguística geral $(2012)^{3}$, intitulada Sobre a essência dupla da linguagem, cuja leitura motiva um resgate de conceitos desenvolvidos no Curso de linguística geral $(1975)^{4}$, sobretudo os de arbitrário, de relação e de valor. Busca-se mostrar, na primeira seção do texto, o parentesco existente entre esses

${ }^{1} \mathrm{O}$ pensamento de Saussure é resgatado do Curso de linguística geral (1975) - livro organizado por Albert Séchehaye e Charles Bally - e do livro Escritos de linguística geral (2012) constituído pela edição de manuscritos descobertos, em 1996, na residência da família Saussure - organizado por Simon Bouquet e Rudolf Engler.

${ }^{2}$ Vale destacar, aqui, que Ducrot criou em 1983, com a colaboração de Jean-Claude Anscombre, a Teoria da Argumentação na Língua (ANL, daqui em diante) - uma semântica linguística fundamentada em princípios e conceitos saussurianos, também chamada Semântica Argumentativa.

${ }^{3}$ Daqui em diante, será utilizada a sigla ELG para fazer referência à obra.

${ }^{4}$ Daqui em diante, será utilizada a sigla CLG para fazer referência à obra. três conceitos e o quão fundamentais eles se revelam, quando se busca compreender o funcionamento da linguagem e a capacidade do sistema para fazer com que as entidades linguísticas ${ }^{5}$ produzam sentido. A partir daí, mostra-se a impossibilidade de distinguir sentido próprio de sentido figurado.

$\mathrm{Na}$ segunda seção, busca-se explicitar, com o olhar da ANL - principalmente com base nos conceitos de orientação e de valor argumentativo e nos pares conceituais significação-sentido e fraseenunciado - que, uma vez assumidos os princípios e conceitos saussurianos como fundamentos epistemológicos da constituição semântica de entidades linguísticas, é preciso radicalizar a tradicional distinção denotação-conotação. Por fim, organizam-se os argumentos teóricos utilizados por Saussure e Ducrot para não distinguir sentido próprio de figurado, esclarecendo, desse modo, a questão levantada no título.

\section{Por uma não distinção de sentido próprio de sentido figurado em Saussure}

Inicialmente, a fim de pensar sobre a constituição de sentido no sistema, mais especificamente a propósito da não distinção de sentido próprio de figurado na linguagem - segundo o pensamento de Ferdinand de Saussure - é preciso evocar, fundamentalmente, os conceitos de arbitrário, de relação e de valor. É, portanto, ao CLG (1975), aos ELG (2012) e aos leitores de Saussure, Simon Bouquet (2000) e Loïc Depecker (2012), que se recorre ao longo desta seção.

Para abrir a discussão aqui proposta, convém salientar que, desde 1916 - data de publicação do CLG -, ao mesmo tempo que o conceito de arbitrário tem sido consensualmente considerado muito importante para os estudos da linguagem, também há uma tendência de deixá-lo esquecido ou de tratá-lo como secundário. É consensual na área de Letras e Linguística, entre professores e pesquisadores, a

${ }^{5}$ Termo utilizado por Carel e Ducrot (2005) para fazer referência à palavra, ao enunciado e ao discurso, notadamente, já utilizado por Saussure (ELG, 2012, p. 33-34). 
ideia da negatividade do valor linguístico. Poucos são, no entanto, os profissionais que realmente se têm movimentado para assumir a mudança de paradigma de ciência que essa noção implica.

Pensar sobre o arbitrário do signo é, antes de tudo, perceber, de acordo com Depecker (2012, p. 85), que, "ao postular que o signo é um todo constituído de uma forma e de um sentido, Saussure rompe com a tradição que geralmente concebe o signo em si mesmo, opondo-o à ideia e à coisa". Considerar apenas o contrato entre a ideia e o símbolo, como o fizeram os filósofos e os lógicos, por exemplo, significa reduzir a língua a uma nomenclatura de objetos que seriam dados previamente. Para Saussure, o signo não deve imitar ou reproduzir o real, pois é um grupo "significantesignificado", forma e sentido mesclados, sendo que o sentido, segundo Depecker (2012, p. 86), "está pelo menos no signo e entre os signos na medida em que ele entra em oposição com outros signos em um sistema dado".

O conceito de arbitrário, para Saussure, apresenta-se, de acordo com Bouquet (2000), ao menos sob duas grandes relações: na relação interna ao signo e na relação sistêmica do signo. O primeiro tipo de arbitrariedade diz respeito "ao fato de que um significante dado corresponde a um significado dado" (BOUQUET, 2000, p. 234), relação que pode ser vista a partir de três ângulos: a) pelo significante, considerando que é arbitrário que certo significado seja a ele ligado; b) pelo significado, considerando que a sua ligação com determinado significante é arbitrária e c) pela própria relação: "é arbitrário que esse significante e esse significado sejam ligados no signo" (BOUQUET, 2000, p. 234). Daí a ausência de motivação do signo com a realidade, isto é, por exemplo, a ausência de relação entre o signo com o objeto do mundo extralinguístico. No CLG, o exemplo mais fidedigno a respeito do arbitrário interno do signo encontra-se no seguinte trecho: "a ideia de 'mar' não está ligada por relação alguma interior à sequência de sons $m$-a-r que lhe serve de significante; poderia ser representada igualmente bem por outra sequência" (CLG, 1975, p. 81-82).
O segundo tipo de arbitrário diz respeito ao seu funcionamento no interior do próprio sistema linguístico, ou, nas palavras de Bouquet (2000, p. 235), concerne "ao 'corte' realizado por um signo na substância ao qual ele dá forma". Nele, encontram-se outros dois tipos de arbitrário: um relacionado ao sistema fonológico e outro, ao sistema semântico de uma dada língua. Diante disso, pode-se perceber que o fenômeno da arbitrariedade diz respeito à própria natureza da língua. Conforme palavras de Ducrot (1987, p. 68), no texto Estruturalismo, enunciação e semântica, "pode-se colocar, na base do estruturalismo em matéria de linguagem, o princípio saussuriano do arbitrário linguístico, princípio geral de que o arbitrário do signo é somente uma aplicação particular".

Assumidas essas noções preliminares sobre 0 arbitrário, pode-se relacioná-las com os conceitos saussurianos de relação e de valor. Para tanto, é importante chamar atenção para a frase que inicia a quarta seção ${ }^{6}$ do capítulo IV $^{7}$ do $\operatorname{CLG}(1975$, p. 139, grifos do autor), depois de já se ter conceituado o valor linguístico: "Tudo o que precede equivale a dizer que na língua só existem diferenças". Essa frase não só introduz a discussão sobre a noção de valor na totalidade do signo, como deve radicalizar noções equivocadas sobre língua, dentre as quais a crença, por exemplo, de que a língua pode ser entendida como uma espécie de nomenclatura que fornece etiquetas a serem aplicadas sobre as coisas do mundo.

Partindo desse princípio saussuriano de que na língua só existem diferenças - sem a presença de termos positivos com os quais geralmente as diferenças se estabelecem - compreende-se, ainda, que tudo é negativo na língua. Conforme se pode ler nos ELG (2012, p. 65, grifos do autor) a esse respeito, "Não há, na língua, nem signos nem significações, mas DIFERENÇAS de signos e DIFERENÇAS de significação". Negar essa tese significa rejeitar a noção de língua como sistema e -

\footnotetext{
${ }^{6}$ Esta seção intitula-se "4. O signo considerado na sua totalidade" (CLG; 1975, p. 139).

${ }^{7}$ O título do capítulo IV é "O valor linguístico" (CLG; 1975, p. 130).
} 
contrariamente ao que postulou Saussure (CLG; 1975, p. 131) - passar a assumir que a língua é substância e não forma.

Partindo, pois, dessa noção de sistema linguístico em que tudo funciona simultaneamente, verifica-se que as noções de arbitrário, de relação entre signos ${ }^{8}$ e de valor linguístico deixam muito clara a ideia de que a língua não reflete a realidade, mas a constrói. Acaba-se completamente com a possibilidade de se acrescentar elementos impostos de fora da língua na constituição semântica, por exemplo. Leiam-se palavras do CLG:

Por sua vez, a arbitrariedade do signo nos faz compreender melhor por que o fato social pode, por si só, criar um sistema lingüístico. A coletividade é necessária para estabelecer os valôres cuja única razão de ser está no uso e no consenso geral: o indivíduo, por si só, é incapaz de fixar um que seja. (CLG; 1975, p. 132).

Essa passagem do CLG permite verificar claramente que, sem a existência do uso e da coletividade do sistema linguístico, o estabelecimento de qualquer que seja o valor torna-se impossível. Os valores linguísticos nascem, portanto, do compartilhamento social do sistema e das relações que se estabelecem no seu interior. Desse modo, pode-se afirmar que todos os termos são solidários intralinguisticamente, e o valor de qualquer que seja o termo resulta da presença simultânea de outros. É o que se pode verificar no esquema abaixo:

Figura 1: Esquema de solidariedade dos termos

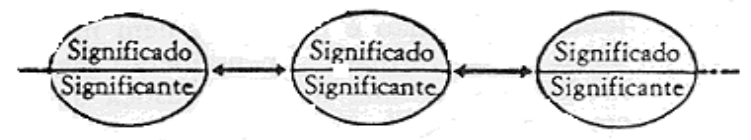

Fonte: CLG (1975, p. 133)

Decorre daí a impossibilidade de continuar distinguindo-se sentido próprio de figurado. Na nota 23 da primeira parte dos ELG (2012, p. 67), a propósito dessas duas noções semânticas, Saussure afirma que "Não há diferença entre o sentido próprio e

${ }^{8}$ Como se pode verificar no $C L G(1975$, p. 142-147), as relações entre signos, no interior do sistema, são sintagmáticas, as que existem in praesentia - através das quais dois ou mais termos existem numa série efetiva - e associativas, as que existem in absentia, as que unem termos numa série mnemônica virtual. o sentido figurado das palavras (ou: as palavras não têm mais sentido figurado do que sentido próprio) porque seu sentido é eminentemente negativo". Para melhor esclarecer essa noção, Saussure (ELG; 2012, p. 67) exemplifica que, em um enunciado como És o sol da minha vida!, usa-se sol, porque não se poderia empregar luz para a mesma posição. Ao mesmo tempo, se existisse, em francês, um termo que significasse claridade do sol, seria absolutamente duvidoso, segundo o mestre, que ainda se empregaria sol na "locução supostamente figurada que foi empregada". Possivelmente o termo que se utilizaria seria muito mais expressivo. São, portanto, as oposições com termos relativamente apropriados como estrela, astro, alegria, encorajamento, etc - que produzem a imagem de sol.

Assim sendo, visto que o signo não evoca objetos materiais, como o quiseram os lógicos, por exemplo - a não ser por via negativa -, não há mais nada capaz de precisar o seu sentido. Ocorre, entretanto, que, fora do sistema, conforme se lê nos ELG (2012, p. 69), relativamente à questão de sinonímia, a essência de determinados objetos materiais - como a de sol, água, ar, árvore, etc tende a dar à palavra uma significação positiva. Todas essas denominações, consoante os ELG (2012, p. 69), são, "na realidade", igualmente negativas, uma vez que significam apenas com relação às ideias inseridas em outros termos (igualmente negativos). Entretanto, não há nenhum objeto, segundo Saussure (ELG; 2012, p. 69, grifo do autor), a cuja "denominação não se acrescente uma ou mais ideias, ditas acessórias mas, no fundo, exatamente tão importantes quanto a idéia principal" [sic].

Dito de outro modo, pode existir significação positiva fora do sistema, mas, nele, a significação é essencial e exclusivamente negativa. Dessa forma, ainda de acordo com Saussure (ELG; 2012, p. 69-70), não mais se acredita em uma significação absoluta que se aplica a um objeto determinado, como tradicionalmente se supunha. É por esse motivo, a título de exemplificação, que se faz necessário modificar o termo para o mesmo objeto, chamando a 
luz de claridade, de luar, de iluminação, etc; e que o nome de um "mesmo objeto" serve para muitos outros: a luz da história, as luzes de uma reunião de sábios, etc. Ainda segundo os ELG (2012, p. 73), "se a idéia positiva de suplício fosse a verdadeira base da idéia de suplício, seria totalmente impossível falar, por exemplo, 'do suplício de usar luvas muito apertadas', que não tem a menor relação com os horrores da grelha e da roda" [sic].

Observa Saussure (ELG; 2012, p. 71) que, desde a idade dos quinze ou dezesseis anos, já se tem um senso aguçado do que está contido, não apenas na palavra em si, mas em milhares de outras palavras. Por isso, é evidente que o sentido repousa no puro fato negativo da oposição de valores. Nas palavras do mestre (ELG; 2012, p. 71), "o tempo materialmente necessário para conhecer 0 valor positivo dos signos nos seria, cem vezes e mil vezes, insuficiente". Desse modo, como nenhum signo está limitado ao total de ideias positivas que concentra em si mesmo - como se define negativamente pela presença simultânea de outros signos - é absolutamente inútil procurar qual é o total de significações de uma palavra.

Para encerrar as reflexões feitas ao longo desta seção, ainda a propósito da não distinção de sentido próprio de sentido figurado, observem-se palavras de Saussure:

E esse mesmo fato, puramente negativo, da oposição com as palavras comparáveis, é também o único que gera a precisão dos empregos "figurados"; nós negamos, na realidade, que eles sejam figurados, porque nós negamos que uma palavra tenha uma significação positiva. Toda espécie de emprego que não cai no raio de ação de uma outra palavra não é apenas parte integrante, mas é também parte constitutiva do sentido dessa palavra, e essa palavra não tem, na realidade, outro sentido além da soma dos sentidos não reclamados. (ELG; 2012, p. 74).

$\mathrm{Na}$ próxima seção, apresentam-se os pressupostos teóricos da ANL - teoria semântica filiada a Saussure - também sobre a não distinção de sentido próprio, tradicionalmente chamado denotativo, de um sentido figurado, chamado de conotativo.

\section{Por que não distinguir sentido denotativo de sentido conotativo em Ducrot?}

Para que se possa esclarecer a questão levantada no título desta seção, é preciso, já de início, revisitar os próprios fundamentos epistemológicos da Teoria da Argumentação na Língua (ANL), visto que essa teoria está destinada a se opor à concepção tradicional de sentido. Na primeira conferência de « Polifonía y argumentación », Oswald Ducrot (1990, p. 49) explica que, nas concepções tradicionais de sentido, geralmente se distinguem, no sentido de um enunciado, três tipos de indicações: as objetivas que consistem em uma representação da realidade -, as subjetivas - que indicam a atitude do locutor frente à realidade - e as intersubjetivas - que se referem às relações do locutor com as pessoas a quem se dirige.

De acordo com a concepção tradicional, Ducrot (1990, p. 50) salienta que o sentido de um enunciado como Pedro é inteligente contém um aspecto objetivo porque descreve Pedro, um aspecto subjetivo porque indica a admiração do locutor por Pedro e um aspecto intersubjetivo porque permite ao locutor pedir a seu destinatário que, por exemplo, confie em Pedro ou, ao contrário, desconfie dele. Tradicionalmente, costumase chamar denotação a esse aspecto objetivo e conotação aos outros dois aspectos.

No entanto, buscando suprimir essa separação, a ANL não acredita que a linguagem possua uma parte objetiva nem que os enunciados possam dar acesso direto à realidade, pois, segundo esclarece Ducrot (1990, p. 50), se a linguagem descreve a realidade, sempre o faz por intermédio dos aspectos subjetivo e intersubjetivo. Falar significa, segundo essa perspectiva, tratar de construir e de impor aos outros uma certa apreensão argumentativa da realidade. Diante disso, fica claro que a ANL se mantém fiel ao modo saussuriano de olhar para a constituição do sentido, sobretudo no que diz respeito aos princípios propostos no capítulo IV do CLG (1975, p. 130-141), sobre a teoria do valor.

No Prefácio para o livro O Intervalo Semântico, de autoria de Carlos Vogt (2009), Oswald Ducrot - 
estudioso da filosofia clássica ${ }^{9}$ - explicita a teoria da alteridade, tal como proposta por Platão, em $O$ Sofista, no fundamento da teoria do valor linguístico de Saussure. Para melhor entender essa questão, vale salientar que, no referido texto filosófico, tendo empreendido 0 inventário das categorias fundamentais da realidade ou "gêneros primeiros" - 0 Movimento, o Repouso, o Mesmo e o Ser -, Platão acrescenta uma quinta categoria - o Outro. A partir daí, de acordo com Ducrot (2009, p. 10), o Outro passa a ser entendido como o gênero dos gêneros e o fundamento de todos os outros: "Da essência do Outro, diremos que ela circula através de todas, porque se cada uma delas, individualmente, é diferente das demais, não é em virtude de sua essência, mas de sua participação na natureza do Outro".

Desse modo, explicando Platão, Ducrot (2009) destaca que o Movimento, por exemplo, é aquilo que ele é em virtude de que ele é outro, diferente do Repouso, do Mesmo, etc. $E$ não é senão isso o que o CLG faz no capítulo sobre o valor linguístico. Nas palavras de Ducrot (2009, p. 10-11), "a oposição é, para Saussure, constitutiva do signo da mesma forma que a alteridade é, para Platão, constitutiva das idéias. O valor de uma palavra - ou seja, sua realidade lingüística - é o que a opõe às outras. Indo mais longe, é a de se opor às outras" [sic]. E, como visto na seção anterior, o valor de um signo sempre é dado numa relação negativa com os outros signos que o rodeiam. Querer atribuir-lhe uma característica positiva significa trair a própria natureza do sistema. Assim, encontrando a alteridade na própria essência da linguagem, passa-se a reconhecer que a língua é um lugar de intersubjetividade, um lugar onde se encontra o Outro, onde a realidade é tema de um debate entre Eu e Outro.

Dessa forma, a descrição, também chamada de aspecto objetivo, é feita, conforme Ducrot (1990, p. 51), por meio da expressão de uma atitude e de um chamado que o locutor faz ao interlocutor. Por esse

\footnotetext{
${ }^{9}$ Para melhor conhecer o percurso científico de Oswald Ducrot e também os fundamentos filosóficos da ANL, pode-se consultar o livro "Les risques du discours: Rencontres avec Oswald Ducrot ", publicado com o apoio da Universidade de Luxemburgo, em 2013.
}

motivo, a ANL unifica os aspectos subjetivo e intersubjetivo no que Ducrot (1990) chama de valor argumentativo dos enunciados. Para melhor entender, o valor argumentativo de uma palavra como inteligente pode ser entendido como a orientação que essa palavra dá ao discurso. Seriam continuações possíveis de inteligente, por exemplo, os segmentos (a) portanto merece confiança, (b) portanto foi aprovado, etc. Sob a condição de mudança de conector e acréscimo de uma negação, porém, também se poderia continuar, por exemplo, com (a) no entanto não merece confiança, (b) no entanto não foi aprovado, etc.

Assim sendo, o emprego de uma palavra possibilita ou impossibilita uma certa continuação do discurso, e o valor argumentativo dessa palavra define-se, segundo Ducrot (1990, p. 51, tradução nossa), como "o conjunto dessas possibilidades ou impossibilidades de continuação discursiva que seu emprego determina ${ }^{10 "}$. Veja-se, no esquema a seguir, como se constrói o valor argumentativo e como o aspecto descritivo é feito pelos outros dois aspectos:

Figura 2: Esquema de constituição do valor argumentativo

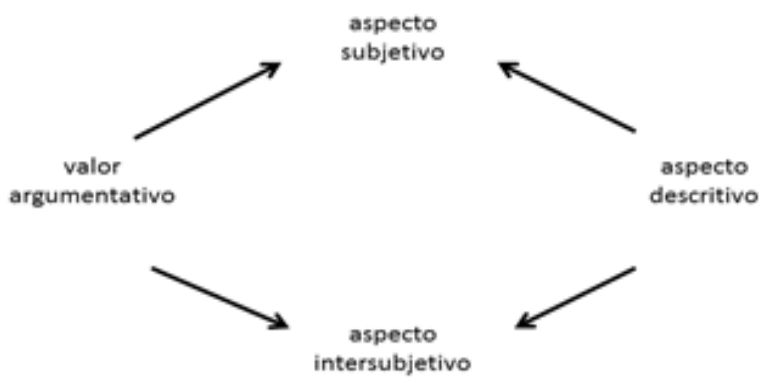

Fonte: Ducrot (1990, p. 52)

Em vista disso - ampliando o conceito saussuriano de valor linguístico - Ducrot (1990) afirma que o chamado valor argumentativo deve dar conta dos principais efeitos subjetivos $e$ intersubjetivos do enunciado e deve ser considerado o nível fundamental da descrição semântica. De acordo com essa perspectiva, o enunciado e o discurso definem-se pelas possibilidades de resposta

\footnotetext{
10 "es el conjunto de esas posibilidades o imposibilidades de continuación discursiva que su empleo determina".
} 
que abrem e por aquelas que fecham. Desse modo, a realidade dos enunciados e discursos não está só neles, mas também fora deles, na sua relação com outros enunciados e discursos, cujo uso eles autorizam ou proíbem.

Para a Semântica Argumentativa, o enunciado é uma entidade elementar concreta, empírica e irrepetível, que, segundo Ducrot (1990, p. 53), pode ser observada quando se escuta as pessoas falarem. É também considerado como a manifestação particular de uma frase, isto é, como a sua ocorrência hic et nunc ${ }^{11}$. Dessa forma, dizendo-se, por exemplo, Faz bom tempo duas vezes, em momentos diferentes, estar-se-á diante de dois enunciados diferentes. Esses mesmos fenômenos ocorrem com o discurso, que, de nível complexo, é constituído por uma sequência linear de enunciados.

Enquanto o enunciado está, notadamente, para o uso da língua, a frase está para a língua. De acordo com Ducrot (1987, p. 164), a frase é um objeto teórico de nível elementar, uma construção do linguista para explicar a infinidade de enunciados. Por isso, não pertence ao domínio do observável, é repetível e, conforme Ducrot (1984, p. 372), deve ser compreendida "como um conjunto de instruções a partir das quais é possível construir, dada uma situação de enunciação, a interpretação do enunciado e, nomeadamente, o valor informativo deste". O mesmo ocorre com o texto, que pode ser definido como uma sequência de frases pertencente ao nível complexo de realização.

Outra distinção importante é a que se pode fazer entre sentido e significação. Explica Ducrot (1990, p. 57) que, enquanto o sentido é o valor semântico do enunciado, a significação é o valor semântico da frase. Essa distinção - arbitrária e metodológica, segundo o referido linguista, - também apresenta diferença de quantidade e de natureza, uma vez que, quantitativamente, o enunciado diz muito mais do que a frase que realiza, e o sentido carrega certos atos de fala, porque pode constatar, aconselhar, ameaçar, advertir, etc, e isso não está

\footnotetext{
${ }^{11}$ Expressão latina empregada para, respectivamente, indicar o lugar (aqui) e o tempo(agora).
}

marcado na significação da frase (DUCROT, 1990, p. 57).

Já a diferença de natureza pode ser percebida na medida em que a significação consiste em um conjunto de instruções que permitem interpretar os enunciados da frase. Nas palavras de Ducrot (1990, p. 58, tradução nossa), "a significação da frase é uma espécie de 'modo de emprego' que permite compreender o sentido dos enunciados ${ }^{12 " .}$ É, portanto, aberta e diz o que é preciso fazer para encontrar o sentido dos enunciados. Numa estrutura do tipo de $X$ mas $Y$, a exemplo de João é republicano, mas honesto, há uma instrução dada a quem deve interpretar o enunciado dessa frase. De acordo com Ducrot (1990, p. 59), essa instrução orienta para que se busque uma conclusão $r$ de modo que ela seja justificada por $\mathrm{X}$, e uma conclusão não $r$ (isto é, a negação de $r$ ), justificada por Y. Daí a indicação do mas de que quem é republicano não é honesto, sustentada pelo próprio enunciado.

As fases mais atuais da ANL, como a Teoria dos Blocos Semânticos (TBS) - desenvolvida por Marion Carel e Oswald Ducrot na Escola de Altos Estudos em Ciências Sociais, em Paris - distinguem, por exemplo, encadeamento argumentativo de aspecto argumentativo. Essa distinção faz-se relevante aos propósitos das reflexões aqui apresentadas, visto que permite compreender mais claramente a construção do sentido de enunciados.

Antes disso, porém, é preciso esclarecer que, até a TBS, consideravam-se como argumentativas as concatenações semânticas em donc (portanto) entre um signo e outro. Considerava-se que a significação da frase subjacente ao enunciado Meu hotel está perto da faculdade, por exemplo, era constituída por um conjunto de conclusões em portanto que se poderia extrair dela. Entre outras, uma continuação possível de se dar à referida frase seria portanto é fácil chegar. Dizendo-se Meu hotel está perto, seria possível concluir com um segmento como portanto é fácil chegar. Dizendo-se, entretanto, Meu hotel está longe, recusar-se-ia a ida até ele, podendo-se

\footnotetext{
12"la significación de la frase es una especie de 'modo de empleo' que permite comprender el sentido de los enunciados".
} 
concluir com um segmento como portanto é difícil chegar. Verifica-se, assim, que portanto é fácil chegar não está relacionado a um conteúdo descritivoinformacional contido na palavra perto.

De acordo com Carel e Ducrot (2005, p. 13, tradução nossa), "o sentido de uma entidade linguística não é constituído por coisas, fatos, propriedades, crenças psicológicas, nem ideias. É constituído por certos discursos que essa entidade linguística evoca"13. Esses discursos, denominados encadeamentos argumentativos, constituem intralinguisticamente o sentido e se manifestam sob a fórmula $X$ CONECTOR $Y$. Enquanto nas fases anteriores à TBS considerava-se haver apenas o conector portanto (donc) - que constituía, conforme denominam Carel e Ducrot (2005), os encadeamentos argumentativos normativos - Carel (1995) se propôs a considerar, também, o conector no entanto (pourtant), que constitui os encadeamentos argumentativos transgressivos, antes observados como uma anomalia.

Para melhor entender, são exemplos de encadeamentos normativos (1) Pedro é prudente, portanto não sofrerá nenhum acidente e (2) Se Pedro é prudente, então não sofrerá nenhum acidente; e são exemplos de encadeamentos transgressivos (3) Pedro é prudente, no entanto sofreu acidentes e (4) Embora Pedro seja prudente, sofreu alguns acidentes. Segundo explicita Carel (2013), a TBS considera como encadeamentos argumentativos as sequências de duas proposições ligadas por conectores do tipo de portanto, se ou porque (encadeamentos normativos) e as sequências de duas proposições gramaticais ligadas por conectores do tipo de no entanto, mesmo se, ou ainda apesar de que (encadeamentos transgressivos).

Dentro desse domínio teórico, faz-se importante salientar que a chamada interpretação metafórica pode ser vista, de acordo com Schulz (2002, p. 328), como um fenômeno calcado sobre a língua e, por isso, diferentemente do que postulam as

\footnotetext{
13"el sentido de una entidad lingüística no está constituido por cosas, hechos, propriedades, creencias psicológicas, ni ideas. Está constituido por ciertos discursos que esa entidad lingüística evoca".
}

semânticas referenciais, a metáfora não é um reflexo do mundo. Segundo defende Schulz (2002), a concepção literal do sentido reduz a estrutura da língua à do mundo, isto é, a estrutura linguística à extralinguística, fazendo-a perder toda a arbitrariedade. Daí a compreensão de um enunciado como (1) Hoje, na Jordânia, até mesmo o sol chora, com base na ANL, não estar subordinada ao conhecimento do interlocutor sobre o referido dia na Jordânia. Esse saber, segundo Schulz (2002), não é necessário à sua compreensão nem faz parte de seu valor semântico profundo.

Nas palavras de Carel (2011), a significação de uma palavra contém o que se chama de aspecto argumentativo, um predicado que, de natureza teórica e abstrata, representa um conjunto de encadeamentos argumentativos. Esses aspectos da significação, também chamados esquemas argumentativos, constituem valores avaliativos. Não apresentam, contudo, a pretensão de descrever o mundo igualmente o têm as semânticas referenciais. Segundo exemplifica Carel (2011, p. 99), a significação de prudente, por exemplo,contém o aspecto PERIGO DC NEG-FAZER. Daí o predicado argumentativo era perigoso portanto Pedro renunciou ser comparável a ser prudente.

Notadamente, para o momento atual da TBS, os enunciados têm uma dupla função: a de evocar encadeamentos e a de exprimir aspectos. Desse modo, mantendo-se fiel às definições propostas pela ANL sobre a entidade linguística abstrata (frase) e a entidade linguística concreta (enunciado), por exemplo, Carel (2011, p. 100) destaca que a evocação dos encadeamentos mostra que o sentido de um termo comum, como prudente, não é repetido pelos enunciados que o contêm, mas é por eles concretizado.

\section{Considerações finais}

Como se pôde observar ao longo deste texto, as noções de arbitrário, de relação e de valor acabam com a clássica distinção de sentido próprio de sentido figurado. Ao deixar claro, no CLG e nos ELG, que na 
língua só existem diferenças de signos e diferenças de significações, que tudo é negativo no sistema, Saussure rejeita a imposição de elementos do mundo extralinguístico na constituição do sentido das entidades linguísticas. Por esse motivo, verifica-se que o conceito de arbitrário - correlacionado aos conceitos de relação (associativa e sintagmática) e de valor - deve estar no centro das pesquisas em semântica.

Pelo que foi possível verificar ao longo da segunda seção deste texto, foi amparado nesses conceitos saussurianos - especialmente no conceito de valor, fundamentado na teoria da alteridade de Platão - que Oswald Ducrot, juntamente com JeanClaude Anscombre e colaboradores, criou a Teoria da Argumentação na Língua, também chamada Semântica Argumentativa. Em vista disso, mantendose fiel ao modo saussuriano de olhar para a linguagem, Ducrot defende a impossibilidade de distinção do que tradicionalmente se chama denotação e conotação. Mostra, por esse motivo, a impossibilidade de separar um aspecto objetivo dos aspectos subjetivo e intersubjetivo na linguagem e unifica esses dois últimos aspectos no que chama de valor argumentativo, nível fundamental da descrição semântica.

Notadamente, dessa noção de valor argumentativo decorre a noção de orientação argumentativa, também essencial nas pesquisas em semântica, visto que permite perceber que os signos, quando ainda se encontram no eixo das associações, já contêm instruções que autorizam certas continuações discursivas e vetam outras no eixo sintagmático. Por esse motivo, nota-se que as entidades abstratas - frases e textos - fornecem pistas para a construção dos sentidos a serem produzidos nas entidades concretas - enunciados e discursos. Em decorrência disso, segundo o pensamento ducrotiano, o que existe são sentidos diferentes e únicos, produzidos normativa ou transgressivamente, a partir de uma significação. Logo, tanto para Saussure quanto para Ducrot, não há como distinguir sentido próprio de figurado.
Por ser um tema relevante e carente de investigações semântico-enunciativas, tanto nos estudos linguísticos quanto nos estudos literários, pretende-se aprofundar as reflexões iniciadas neste trabalho em pesquisas futuras, a fim de explicar e descrever, a partir do exame de corpora distintos, o funcionamento da produção do sentido na linguagem.

\section{Referências}

BARTHES, Roland. A retórica antiga. In: COHEN, Jean et al. Pesquisas de retórica.Trad. Leda Pinto Iruzun. Petrópolis: Vozes, 1975, p. 147-224.

BOUQUET, Simon. Introdução à leitura de Saussure. São Paulo: Cultrix, 2000.

CAREL, Marion. L'Entrelacement argumentatif. Lexique, discours et blocs sémantiques. Paris: Éditions Honoré Champion, coll. Bibliothèque de grammaire et de linguistique, n.36, 2011.

CAREL, Marion. Pourtant: argumentation by exception. Journal of Pragmatics, v.24, p. 167-188, 1995.

CAREL, Marion; DUCROT, Oswald. La semántica argumentativa:una introducción a la teoría de los bloques semánticos. Tradução: María Marta García Negroni e Alfredo M. Lescano. Buenos Aires: Colihue, 2005.

CAREL, Marion. Tu serás um homem, meu filho. Um prolongamento da doxa: o paradoxo. Desenredo, Passo Fundo, Ed. da Universidade de Passo Fundo, v. 9, n. 2, p. 254-270, jul./dez. 2013.

DEPECKER, Loïc. Compreender Saussure a partir dos manuscritos. Petrópolis, RJ: Vozes, 2012.

DUCROT, Oswald. "Enunciação". In: Enciclopédia Einaudi: linguagem e enunciação. Lisboa: Imprensa Nacional, Casa da Moeda, 1984, v. 2, p. 368-393.

DUCROT, Oswald. O dizer e o dito. Revisão técnica da tradução Eduardo Guimarães. Campinas, SP: Pontes, 1987.

DUCROT, Oswald. Polifonía y Argumentación. Conferencias del Seminario Teoría de la Argumentación y Análisis del Discurso. Cali: Universidaddel Valle, 1990.

DUCROT, Oswald. Prefácio. In: VOGT, C. O Intervalo Semântico: (contribuição para uma teoria semântica argumentativa). 2. ed. rev. São Paulo: Ateliê Editorial/Campinas: Editora da Unicamp, 2009b. p. 9-19. 
SAUSSURE, Ferdinand de. Curso de linguística geral. Organizado por Charles Bally e Albert Séchehaye. Tradução de Antônio Chelini, José Paulo Paes e Izidoro Blikstein. 7. ed. São Paulo: Cultrix, 1975.

SAUSSURE, Ferdinand de. Escritos de linguística geral. BOUQUET, Simon; ENGLER, Rudolf (orgs.) e WEIL, Antoinette (Col.). Tradução Carlos Augusto Leuba Salum e Ana Lucia Franco. São Paulo: Cultrix, 2012. 296p.

SCHULZ, Patrícia. Plaidoyer contre une interprétation des énoncés en termes de «métaphore ». In: CAREL, Marion. Les facettes du dire: hommage à Oswald Ducrot. Paris, 2002, p. 325-339.

\section{COMO CITAR ESSE ARTIGO}

GOMES, Lauro; BARBISAN, Leci Borges. Por que não distinguir sentido próprio de sentido figurado em Saussure e em Ducrot?.Signo, Santa Cruz do Sul, v. 42, n. 73, jan. 2017. ISSN 1982-2014. Disponível em: <https://online.unisc.br/seer/index.php/signo/article/view/7836>. Acesso em: doi:http://dx.doi.org/10.17058/signo.v42i73.7836. 